\title{
Academic Managers` Perspective on Research Management in Higher Education Institutions across Romania
}

\section{Elena Marin ${ }^{\mathrm{a}}$; Simona Iftimescu ${ }^{\mathrm{a}}$; Georgeta Ion $^{\text {ab }}$; Mihaela Stîngu ${ }^{\mathrm{a}}$ and Carmen Proteasa $^{a}$}

${ }^{\mathrm{a} C e n t e r}$ For Development And Training In Higher Education, University of Bucharest

${ }^{\mathrm{b}}$ Universitat Autònoma de Barcelona

\begin{abstract}
This paper seeks to bring into discussion the main traits and their effects on the research management process within Romanian universities from the managers' perspective. Fourteen academic managers took part in a semistructured in-depth interview aimed at presenting and analysing the research management process in higher education institutions. The focus was on academic managers'perspective regarding the current university model, the research culture within universities and the internal strategies used to promote and stimulate research production. Results show the university should be considered an important pillar for economic growth and thus, it must invest in developing more research activities of higher quality, helping to transform knowledge into a profitable investment. Therefore, the university needs to support the development of internal strategies that will help researchers work individually or in teams in order to implement research projects, ensuring that potential inaccuracies, such as lack of institutional support or bureaucracy, are reduced.
\end{abstract}

Keywords: research management; university; Romania. 


\section{Introduction}

The status quo of higher education is in a constant change due to increasing demand in the contemporary society. This brings the necessity of reforming and restructuring the universities in order to become more responsive to the needs of the global knowledge-based society (Marginson, 2010). To do so, universities must invest in strengthening their research capacity not only to contribute to the society's development, but also to find ways to differentiate from other higher education institutions (HEI). This differentiation is generally related to teaching and performing public service, but also to engaging in winning 'competitive research funds from government or industry, because research is the activity that differentiates among and within universities` (Slaughter and Leslie, 1997). Therefore, universities must develop an internal research paradigm (Maassen, 2000).

The literature points out several characteristics of research at university level: it lacks coherent theoretical and methodological frameworks (Scott, 2000), as well as stability and quality (Teichler, 2000) and it tends to be created in broader, transdisciplinary social and economic contexts in response to specific problems in order to meet a range of users' needs (Gibbons et al., 1994). Also, it appears that academic research has a fairly low impact on policy and does not manage to meet the decision-makers' needs (Blunkett, 2000; O'Dwyer, 2004; Levin \& Edelstein, 2010; Cherney, Povey, Head, Boreham, \& Ferguson, 2012).

Engaging in research activities means investing in the process of shifting from a traditional university model centred on teaching to a more complex model, where HEI place a greater importance on academic development regarding three main pillars: teaching, research and economic development. When it comes to the university's mission insofar research is concerned, the first aspect to consider appears to be the development of a research culture within university. An understanding of the research culture is presented by Evans (2009) as a set of shared values, assumptions, beliefs, rituals and other forms of behaviour, whose central focus is the acceptance and recognition of research practice and output as a valued, worthwhile and pre-eminent activity.

\section{Methods}

The data presented in this article are drawn from a project funded by the Ministry of Education through the Romanian National Authority for Scientific Research and Innovation, which aims to analyse the impact of educational research mobilization on policy-making.

The data-gathering process involved four phases, comprising of both quantitative and qualitative data: (1) a targeted survey of 347 academics in the field of education from 17 public universities in Romania; (2) 14 semi-structured in-depth interviews with academic 
managers; (3) 13 semi-structured in-depth interviews with a selection of policymakers/experts in the field of education; and (4) 3 focus groups with a select group of academics, academic managers and policy-makers. Results reported hereby are based on phase 2 .

\subsection{Participants'profile}

Interviews were conducted with 14 academic managers from research intensive universities and research-teaching universities in Romania. The profiles of the interview participants are given in Table 1.

Table 1. Participants' profile

\begin{tabular}{ll}
\hline Participants' profile & N: \\
\hline & \\
Heads of departments & 9 \\
Vice rectors responsible with research activities & 3 \\
Vice deans responsible with research activities & 2 \\
\hline Total & 14 \\
\hline
\end{tabular}

\subsection{Data analysis}

The interviews were conducted over a period of 5 months between March and July 2016, have a duration between 30 and 180 minutes and have later been transcribed and validated with the participants. All transcripts were coded using line-by-line analysis in accordance with Glaser \& Holton's (2004) guidelines on coding for grounded theory. The Maxqda 11 software for qualitative data analysis was used to facilitate coding, data management and promote transparency. The interviews targeted, amongst others, open-ended question about the research management process in higher education institutions, namely the university model, the research culture within universities and internal strategies to promote and stimulate research production. The code used to identify interviews in this article is I1 to I14. 


\section{Results}

\subsection{The university model in transition}

By focusing on the university model in general, the respondents tend to frame universities in a traditional and comprehensive model, that brings together different study areas (vocational, social sciences, social sciences and natural sciences) and describe it as having `a unique complexity that brings together different study areas`(I9).

Making the shift from a teaching centred-university to a research-centred university is a natural process, agrees the dean of one of the oldest universities in Romania: `we can speak of a historical pattern; traditionally, universities' aim was to form the social and political elites, but nowadays the university is already defined by the Humboldtian model focusing on encouraging productive thinking`(I12).

Moreover, some academic managers placed an emphasis on yet another university model: the entrepreneurial university. Therefore, the university should be seen as a communitycentred university that aims at developing a strong collaboration with the social and professional sectors. Academic managers believe the university has to adapt to the entrepreneurship sector and to the economic environment in order to contribute to economic growth, to transform knowledge into a profitable investment and to provide educational services in order to meet the demands of the labour market. The great challenge is to identify the way in which 'academic knowledge brings profit' (I12).

When talking about the research activity within universities, the 'traditional model' is the one that best describes the Romanian universities. This model is asociated with the fact that a research area strictly develops only if a researcher has a particular interest in that topic. One of the interviewees, Head of Department, agrees that:

'the researcher is the one that helps a research area to spread its importance, not viceversa, meaning that the research process is still a sum of individual achievements, rather than a joint effort of a team of researchers` (I14)

Even though there is a desire to move towards a research-centred university, there also appear to be some challenges: the funding mechanisms within universities are exclusively based on the teaching perspective (funding is strictly based on the number of students). This situation is best described by the Dean of an Education Science faculty, who states:

I think there is a problem: we want to move towards a model that is centred on researchbased universities, but funding is granted only on a numerical criteria - the number of students determines the budget that the institution receives`(I11) 


\subsection{Research culture}

When it comes to the research culture within universities, the are some key issues that show there is still no clear vision on this concept, as stated by one of the interviewed academic managers: a coherent culture, at university level, does not exist, neither does a culture of research in general (I8).

The key issues are related to the lack of clear values and the lack of an environment that would foster the impact of research on social development. Other key aspects are related to the fear of cooperation among researchers, a lack of recognition of the researchers' status both within and outside the academia, and the persistence of the `traditional model.

Despite the aforementioned fear of cooperation, at least at a declarative level both individual and team research activities are valued. In terms of individual work, the research activity is closely related to the individual career development: 'it comes to one's interests, concerns, passions` (I10). This represents one particular motivational factor for engaging in research activities, along with the professional and academic prestige deriving from it. When referring to team research, the focus is placed on developing a common theme, particularly for the purpose of bringing a specific topic on the academic and public agendas: 'we intend to work from small groups to larger groups and try to integrate everyone in these activities to highlight and promote the importance of a topic`(I9). Also, the development of research teams can help create an 'ethos which can be shaped only through joint projects that focus on initiative, partnership and involvement (I12), thus contributing to the overall restructuring of the university and research culture. This last statement, which comes to support the importance of developing research teams, is closely related to institutional accountability to promote and support a standard of quality, performance and compliance codes and rules related to research ethics.

\subsection{Internal strategies to promote and stimulate research production}

Following the results of our research, the internal strategies that emerge when it comes to the promotion of research activities could be dived into three main categories: 


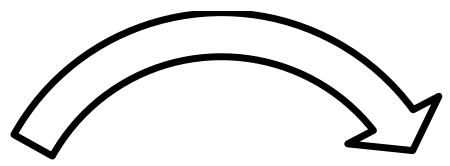

\section{Support for the development of research teams}

\author{
Emphasis on relevant \\ research activities with \\ impact on the research area
}

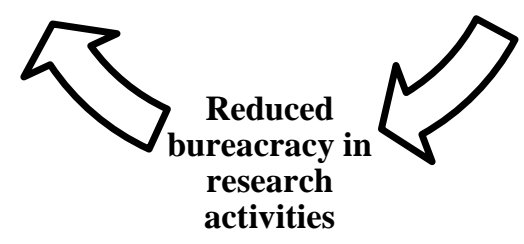

Figure 1. Internal strategies to promote and stimulate research production

When it comes to internal strategies for promoting research activities, the most important aspect is related to the necessity to develop relevant activities, with an impact on the research area, particularly the publication of articles indexed in the ISI Web of Science database:

'the development of studies and articles published in indexed journals with impact factor is encouraged (I1).

Other strategies target the development of different events, such as the Research Excellency Gala, which have been developed throughout the Romanian universities aiming to bring researchers together. Also, academic managers present the importance of being part of a research team and of initiating partnerships with other national or international universities in order to develop joint projects. To do so, the university must provide some guidelines or a research strategy clearly stating that interdisciplinary research teams are encouraged and that researchers are free to choose their affiliation to a research group/team, an action which should be supported by simplified procedures for establishing new research centres within the university departments. Last but not least, academic managers involved in research activities agree that the most important strategy would be the reduction of bureaucracy when it comes to creating a new research centres or to developing research projects, which are generally associated with 'administrative aspects that, in the majority of cases, overwhelm the researchers' (I2). All in all, academic managers acknowledge the need for a more structured institutional framework and support, while maintaining autonomy in pursuing their research interests. 


\section{Conclusions}

The academic managers' perspective on Romanian universities is defined by the universities' shift from the traditional model towards a more entrepreneurial university, as there is an increased awareness of the fact that teaching is not the sole component of a highly qualitative system. Therefore, more investments should be targeted at research activities in order to support future scientific and societal development and the general funding scheme for universities could also be altered to reflect this approach. Also, investing in becoming an entrepreneurial university is, according to Guerrero \& Urbano (2012), the main element that differentiates one university from another, and this distinction arises from institutional arrangements, traditions and characteristics unique to each organization.

Even though the desire to move towards an entrepreneurial university by engaging in research activities becomes more obvious, there are still some challenges to be tackled along the way. One of these challenges refers to the necessity of developing relevant research activities with a real impact on the research area by publishing articles indexed in the ISI Web of Science database. Academic managers participating in the study perceive a higher pressure to publish more, doubled by a sense of urgency, which leads to negative effects including heightened stress levels, the marginalization of teaching, and research that may lack relevance, creativity, and innovation (Miller et al., 2011). This state of affairs is encouraged by the current evaluation system of academics in higher education, which emphasises the research component in the detriment of teaching, whereas the reality in the field mirrors a different image. This contradiction between the split roles of teaching and research in higher education could sometimes lead to research or publishing becoming a purpose in itself, beyond a scientifically-driven initiative that would bring added value both to the area of research and to society at large.

Another challenge is related to the bureaucratic burden attached to conducting research activities. A study shows that $35 \%$ of researchers in Romania consider that bureaucracy in their institutions is preventing them from operating under normal conditions, while $30 \%$ believe that government helps them (Florian, 2006). Academic managers advocate for a more structured framework and for more institutional support, while supporting the researchers' autonomy in pursuing specific research interests, thus contributing to an increase in their personal motivation to pursue more relevant results for the research area, for the higher education institution and its research community, as well as for the society.

In order to overcome these challenges, universities must develop internal strategies that lead to the development of a clear research vision and strategy within universities, which can help academics and researchers to further engage in individual or team research. Whereas academic managers have a central role in ensuring the institutional framework, 
these strategies should be doubled by coherent policies regarding quality assurance, academics' evaluation and university ranking criteria, simplified bureaucratic requirements, as well as a renewed funding strategy for universities and research.

\section{References}

Blunkett, D. (2000). Influence or irrelevance: can social science improve government. Research Intelligence, 71, 12-21.

Cherney, A., Povey, J., Head, B., Boreham, P., \& Ferguson, M. (2012). What influences the utilisation of educational research by policy-makers and practitioners?: The perspectives of academic educational researchers. International Journal of Educational Research, 56, 23-34.

Evans, L. (2009). Developing research capacity in the social sciences: a professionalitybased model. International Journal for Researcher Development, 1(2), 3-19.

Florian, R. (2006). Oamenii de ştiinţă din România şi recunoaşterea rezultatelor lor. Ad $\begin{array}{lllll}\text { Astra } & 5 & (1), & \text { Retrieved } & \text { from }\end{array}$ astra.ro/journal/8/florian_oamenii_de_stiinta.pdf.

Glaser, B., \& Holton, J. (2004). Remodelling Grounded Theory. Forum Qualitative Sozialforschung / Forum: Qualitative Social Research, 5(2). Retrieved from http://www.qualitative-research.net/index.php/fqs/article/view/607/1315

Levin, B., \& Edelstein, H. (2010). Research, policy and practice in education. Education Canada, 50(2), 29-30.

Guerrero, M., \& Urbano, D. (2012). The development of an entrepreneurial university. The Journal of Technology Transfer, 37(1), 43-74.

Maassen, P. (2000). Higher Education Research: The Hourglass Structure and Its Implications in U. Teichler and J. Sadlak (eds.) Higher Education Research: Its Relationship to Policy and Practice, Oxford: Pergamon and IAU Press, pp. 59-67.

Marginson, S. (2010). Higher education in the global knowledge economy. Procedia-Social and Behavioral Sciences, 2(5), 6962-6980.

Miller, A. N., Taylor, S. G., \& Bedeian, A. G. (2011). Publish or perish: Academic life as management faculty live it. Career Development International, 16(5), 422-445. doi:10.1108/13620431111167751

Scott, P. (2000). Higher Education Research in the Light of a Dialogue between PolicyMakers and Practitioners, in U. Teichler and J. Sadlak (eds.) Higher Education Research: Its Relationship to Policy and Practice, Oxford: Pergamon and IAU Press, pp. $123-147$.

Slaughter, S. and L. Leslie (1997), Academic Capitalism. Politics, Policies and the Entrepreneurial University. Baltimore, Johns Hopkins Press, pp. 5, 7, 54, 61.

Teichler, U. (2000). The Relationships between Higher Education Research and Higher Education Policy and Practice: The Researchers' Perspective, in U. Teichler and J. Sadlak (eds.) Higher Education Research: Its Relationship to Policy and Practice, Oxford: Pergamon and IAU Press, pp. 3-34. 